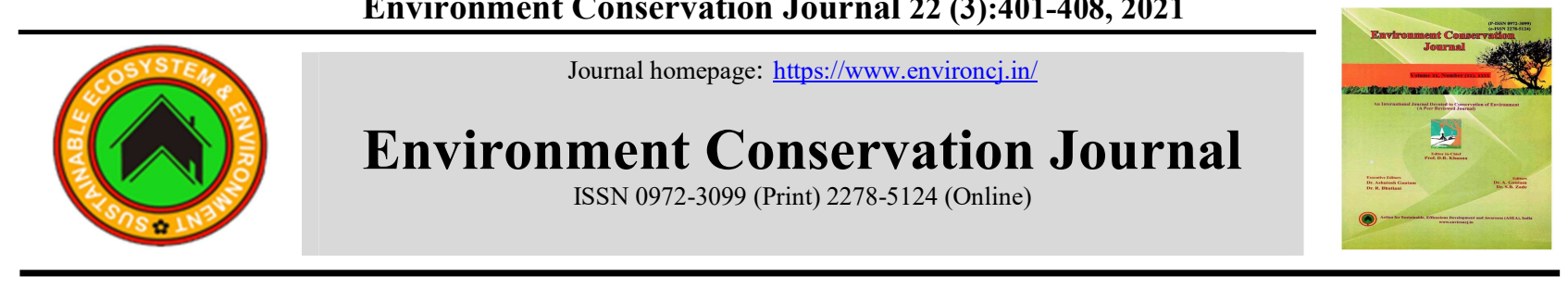

\title{
Opportunities and constraints in hydroponic crop production systems: A review
}

\author{
Sunil Kumar 厕 \\ Department of Soil and Water Engineering, College of Technology and Engineering, MPUAT, Udaipur, Rajasthan, India. \\ Manjeet Singh \\ Department of Soil and Water Engineering, College of Technology and Engineering, MPUAT, Udaipur, Rajasthan, India. \\ K.K.Yadav \\ Department of Soil Science, College of Agriculture, MPUAT, Udaipur, Rajasthan, India. \\ P.K. Singh \\ Department of Soil and Water Engineering, College of Technology and Engineering, MPUAT, Udaipur, Rajasthan, India.
}

\begin{tabular}{|c|c|}
\hline ARTICLE INFO & ABSTRACT \\
\hline $\begin{array}{l}\text { Received : } 28 \text { August } 2021 \\
\text { Revised : } 07 \text { October } 2021 \\
\text { Accepted : } 12 \text { October } 2021 \\
\text { Available online: } 19 \text { December } 2021 \\
\text { Key Words: } \\
\text { Ebb flow system } \\
\text { EC and pH management } \\
\text { Hydroponics } \\
\text { NFT system } \\
\text { Wick system } \\
\text { Water Use Efficiency }\end{array}$ & $\begin{array}{l}\text { Hydroponic crops can be grown using a variety of media and production } \\
\text { systems (NFT system, wick system, drip system, ebb flow system etc.). EC and } \\
\text { pH management are required to successfully handle these hydroponic systems } \\
\text { (water quality and nutrient solution maintenance). These hydroponics systems } \\
\text { have gained rapid adoption due to disciplined management of their resources } \\
\text { and food production. Although the hydroponic system was developed in a } \\
\text { closed-loop system, and substrate nutrition increases production, it is not cost- } \\
\text { effective to develop this system on big scale. It is critical to design a low-cost } \\
\text { hydroponic structure that decreases reliance on human labour and lowers } \\
\text { overall startup cost in order to increase the commercialization of hydroponic } \\
\text { farms. We need more research to develop more productive and cost-effective } \\
\text { organic nutrient solutions and improve hydroponic crop production systems. In } \\
\text { this review paper, we will discuss the opportunity and challenges in hydroponic } \\
\text { crop production systems. }\end{array}$ \\
\hline
\end{tabular}

\section{Introduction}

Food-growing systems must be developed in order to feed the world's rising population in a sustainable manner. For feasible production and conservation of rapidly decreasing land and water supply resources, changing the growth medium is a possibility. Soilless farming is currently a realistic option for cultivating healthy edible plants, crops, or vegetables that may be properly introduced and evaluated (Butler and Oebker, 2006). In addition to substrate culture, farming without soil includes hydroponics, aquaponics, and aeroponics. These hydroponics systems have gained rapid adoption due to disciplined management of their resources and food production (Hussain et al., 2014). Hydroponics may be used to produce a wide range of marketable and regional crops, including tomatoes, peppers, cucumbers, strawberries, and green vegetables. Lettuce and spinach are the most promising species to grow in aquaculture and hydroponics systems because of their high growth and nutrient uptake ability (Sharma et al., 2018). Hydroponics is a technique for growing plants without soil by immersing their roots in a nutrient solution. This approach aids in addressing the difficulties of climate change and production system management in order to reduce malnutrition and make effective use of natural resources (Hussain et al., 2014). Aeroponics technology is similar to hydroponics in many ways, with the exception that plants in aeroponics are grown with thin droplets of nutrient solution (a mist or aerosol). W J Shalto Duglas, an English scientist who constructed a laboratory in the Kalimpong district of West Bengal and produced the book "Hydroponics: The Bengal system," recognized hydroponics in India in 1946. The term

Corresponding author E-mail: sunil.parihar8239@gmail.com

Doi: https://doi.org/10.36953/ECJ.2021.22346

This work is licensed under Attribution-Non Commercial 4.0 International (CC BY-NC 4.0)

(C) ASEA 
hydroponics comes from two Greek words: hydro, which means "water," and ponic, which means "to work." Hydroponics is related to growing plants in soil-less and nutrient-rich solutions to increase the production of crops. The water used for the production of crops should be clean and free from microbial contamination and chemical agents (Suma et al., 2020).

Hydroponic greenhouse systems eliminate the requirement for additional land for crop production. To boost output by reducing water, fertilization, and pesticide use, which can be reached through greenhouse farming? The efficient use of sunlight is a benefit of hydroponic greenhouse farming. Light falls on both the upper and lower parts of the plant in a hydroponic greenhouse. Both top and lower fruits develop at the same time due to the uniform dispersion of light (Despommier, 2009).

Hydroponics farming allows people to grow forage and food in areas where conventional agriculture is not possible, desert-like regions with arid climates (Okemwa, 2015). The hydroponic method allows people to consume and enjoy locally grown products while also increasing their food production. In heavily populated metropolitan areas where there is no suitable land for farming, hydroponics can be used (Schnitzler, 2012). Hydroponic methods are helpful in areas with warm climates or inadequate sunlight (Jensen and Malter, 1995). Hydroponic systems for crop production are rapidly developing and improving nowadays (Griggs et al., 2019).

\section{Historical background of hydroponic}

Julius von Sachs, a well-known German botanist, demonstrated for the first time in 1860 that plants could be grown to maturity in the lack of soil using a specific nutritional solution. Professor William Gerrick invented the term hydroponics to describe the growth of plants with roots suspended in water containing necessary nutrients in the early 1930s. In 1940, Purdue University researchers created the feeding system. Hydroponics gardens were established in Arizona, Abu Dhabi, Belgium, California, Denmark, Germany, Holland, Iran, Italy, Japan, and Russia throughout the 1960s and 1970s (Sardare et al., 2013). Due to hasty industrialization and urbanization, not only the cultivable land is diminishing but the conventional farming techniques are also having a significant negative influence on the environment. In present situation, soilless farming can be successfully introduced and considered as an alternative option for growing nutritious food plants, healthy edible vegetables, or crops (Sharma et al., 2018).

\section{Hydroponic structures}

Plants cultivated in hydroponic culture have their roots suspended directly in a nutrient solution. So it is also named by Liquid hydroponics system. In this system, plant roots are supported by soil pellets, peat moss, perlite, and rock wool. Hundreds of variations of hydroponic systems are available when we build a hydroponic structure for growing plants. However, here we are discussing five types of hydroponic systems under which all variations are located.

1. Wick System, 2. Drip system, 3. Ebb-Flow, 4. Nutrient Film Technique (NFT)

\section{Wick System}

In the wick system, the root of the plant is fed by a strip of porous material that is immersed in a liquid that is fed to the capillary in a tray or other absorbent medium. The system is installed above the feed solution tank at a minimum distance (Grigas et al., 2019). It is the most basic hydroponic system, requiring no pumps, electricity, or aerators (Shrestha and Dunn, 2013). Plants are kept in an absorbent medium such as coco-peat, perlite, or vermiculite, with a nylon wick running through their roots to hold nutrient solution. Capillary action transports water and nutrients to plants. This technique works well for small plants, herbs, and spices, but not for plants that need a lot of water. The tank containing the nutrient solution, the growing container, the growing media, and the wicks are the four essential components of a hydroponic wick system (Sharma et al., 2018).

\section{Drip system}

The drip system is a fast-growing hydroponic system nowadays. It contains a pump to feed the plants with nutrients and water regularly. This system is well-known as a micro-irrigation system. This technique employs little hoses to provide nutritional solution or water directly to the root zone of the plant (Palm et al., 2018). This technology has the advantage of using less water and performing well in both soil and hydroponics growing conditions (Grigas et al., 2019).

The drip hydroponic method is the most used method, with the help of a water pump, water or 
nutrient solution from the tank is directly delivered to the roots of each plant in right proportion (Rouphael and Colla, 2005). Plants are usually planted in a medium that is somewhat absorbent so that the nutrient solution drips down slowly. Various crops can be cultivated organically, with as much water conservation as feasible (Sharma et al., 2018).

\section{Ebb flow system}

This was the first commercial hydroponic structure, and it works on the flood and drain method. The fertiliser solution and water from the reservoir rise through a water pump in the floodplain until they reach a specified level and stay there for a set period of time, providing nutrients and moisture to the plants. In addition, it is possible to grow a broad variety of crops, but algae, root rot, and mold problems are very common (Nielsen et al., 2006).

\section{Nutrient film technique (NFT)}

NFT was developed by Dr. Allen Cooper in England in the mid-1960s to overcome the shortcomings of the ebb and flow system. A nutrient solution or water circulates throughout the system; and without any time control, the water enters the rising tray by using the pump (Domingues et al., 2012). The system is tilted at an angle, allowing the nutrient solution to flow through the roots and into a reservoir below. The plants' roots are suspended in a hydroponic nutrition solution and placed in a conduit or pipe. The roots, on the other hand, are susceptible to fungal infection because they are constantly submerged in water or nutrients. Many leafy greens can be easily grown in this system, and it is broadly utilized for commercial lettuce production (Sharma et al., 2018). The main quality of this technology is irrigation and the solution of nutrient is recycled several times (Burrage, 1992). This system is usually adapted for various plant growths and is a perfect solution for growing short-cycle plants such as cereals, lettuce, etc. This technique is similar to the ebb and flow methods for numerous reasons. It consists of a recirculation pipeline that allows the conversion of used water or nutrient solution from the reservoir into a container that can be cleaned. Also, these growing systems rely entirely on water pumps to provide solution recirculation and nutrition to the plants (Grigas et al., 2019).

\section{Advantages of hydroponics}

There are so many advantages of growing plants under hydroponic system as compared to conventional system. Because the nutrients are given directly to the roots, the plants develop faster and have smaller roots, allowing them to be grown closer together. Hydroponic system provides increased production per acre along with effective nutrient controls, high-density seeding, and improved production quality. It is also efficient for areas of the world where there is a lack of cultivable or fertile land for agriculture (Sardare et al., 2013).

Hydroponic technology is a sparkling and comparatively simple technique and it reduces or eliminates the use of insecticides to reduce or eliminate the possibility of soil-borne diseases, insect or insect infestation to plants. This method is particularly useful in locations where environmental pressure (cold, heat, sweet, and so on) is a significant problem (Polycarpou et al., 2005). Because hydroponic crops are not impacted by weather fluctuations, they can be cultivated all year and considered off-season (Manzocco et al., 2011). Furthermore, commercial hydroponic systems are intended to minimise labour and eliminate many traditional agricultural procedures, such as weeding, spraying, watering, and ploughing, by operating automatically (Jovicich et al., 2004). Hydroponics saves a lot of water in the form of irrigation and doesn't require any other kinds of spray, so there's never any problem of waterlogging. Pests and illnesses may be easily controlled, whilst weeds are virtually non-existent. When compared to conventional farming, larger yields can be attained because to a higher number of plants per unit (Sharma et al., 2018). The hydroponic system uses fewer pesticides, produces more, and saves water (Arias-fermandz et al., 2000; Buchanan et al., 2013).

Hydroponic greenhouse systems are the most efficient way to grow high-nutrient-value crops (Jones, 2012). Hydroponic systems have more benefits than drawbacks (Banda-Guzman and Lopez-Salazar, 2014). The percentage of land, nutrients, water requirement, and growing time are low in the case of hydroponic greenhouse systems (Banerjee and Adenauer, 2014). In the case of hydroponic greenhouse systems, plants are never 
under stress because nutrients and water are always available to the plant roots (Ruth, 2009; Khan et al., 2018).

\section{Limitations of hydroponics}

Although soilless farming is an advantageous technique, it has significant limitations. Technical knowledge and high initial cost are the basic requirements for commercial-scale farming. Waterborne diseases can easily spread from one plant to the next in a hydroponics system since the plants share similar nutrient (Ikeda et al., 2006). Hot climate and a lack of oxygen can reduce production and lead to crop loss. The necessity of maintaining the $\mathrm{EC}, \mathrm{pH}$, and optimum concentration of the nutritional solution cannot be overstated. Finally, lighting and energy supplies are required to keep the system running in a safe environment (Sharma et al., 2018). Hydroponics is becoming a more popular method of growing vegetables. However, one of the major drawbacks of hydroponics is that certain crops can quickly accumulate large levels of nitrate- $\mathrm{N}\left(\mathrm{NO}_{3} \pm-\mathrm{N}\right)$ from the system (Guo et al., 2019).

According to Tyson et al. (2004) the hydroponic structure's world should be able to support at least 40 large plants (tomatoes, banana peppers, and bell peppers) and 72 little plant (spinach, lettuce, and strawberries). Temperature, light intensity, carbon dioxide concentration, and humidity must all be monitored in hydroponic greenhouses using an Arduino-based climate control monitor system (Hochmuth and Hochmuth, 2001).

Several aspects should be considered during the installation of an Arduino-based climate control system, including (system availability, system efficiency, and transportation cost, among others), and the initial cost of the system is also supported by these elements (Taig, 2012). According to a literature review, the cost of an Arduino-based climate control system for a commercial hydroponic system is between US\$500-2000 (Grewal et al., 2011; Takakura, 2014; Khan et al., 2018; Manju H.M., et al., 2020).

\section{Management of nutrients in hydroponic}

In hydroponics, due to the low nutrient-buffering capacity of the system and the ability to make quick adjustments, constant monitoring is required. The availability of nutrients from the nutrient delivery system, as well as the response of plants to nutrients, are two aspects of nutrition that must be considered. The optimal time for monitoring the nutritional solution is between 6 am to $8 \mathrm{am}$. To avoid damage and the spread of diseases, the roots should be mulched instead of the leaves (Sardare et al., 2013). The sources of nutrients along with their characteristics are given in the table 1.

Table 1: Sources of nutrients and their properties (Sardare et al., 2013)

\begin{tabular}{|l|l|l|}
\hline Source & Components & Properties \\
\hline $\begin{array}{l}\text { Calcium nitrate } \\
\mathrm{Ca}\left(\mathrm{NO}_{3}\right)_{2}\end{array}$ & $\mathrm{Na}, \mathrm{Ca}$ & $\begin{array}{l}\text { Salt that is very } \\
\text { soluble }\end{array}$ \\
\hline $\begin{array}{l}\text { Boric acid } \\
\left(\mathrm{H}_{3} \mathrm{BO}_{3}\right)\end{array}$ & $\mathrm{B}$ & $\begin{array}{l}\text { Boron's best } \\
\text { source }\end{array}$ \\
\hline Iron chelate & Fe Cit & Iron's best source \\
\hline $\begin{array}{l}\text { Potassium } \\
\text { nitrate }\left(\mathrm{KNO}_{3}\right)\end{array}$ & $\mathrm{N}, \mathrm{K}$ & $\begin{array}{l}\text { Salts that are very } \\
\text { soluble }\end{array}$ \\
\hline $\begin{array}{l}\text { Potassium } \\
\text { phosphate } \\
\text { monobasic } \\
\mathrm{KH}_{2} \mathrm{PO}_{4}\end{array}$ & $\mathrm{P}, \mathrm{K}$ & $\begin{array}{l}\text { Phosphorus } \\
\text { deficiency should } \\
\text { be evaluated }\end{array}$ \\
\hline $\begin{array}{l}\text { Magnesium } \\
\text { sulfate }\left(\mathrm{MgSO}_{4)}\right.\end{array}$ & $\mathrm{S}, \mathrm{Mg}$ & $\begin{array}{l}\text { Very cheap, } \\
\text { highly soluble, } \\
\text { and pure } \\
\text { substance. }\end{array}$ \\
\hline
\end{tabular}

\section{Electrical conductivity (EC) and pH} management

In hydroponics, plant nutrients are dissolved in water and are generally inorganic. Different chemical combinations provide all 17 components required for plant growth. The most prevalent nutrient solution for hydroponic systems is Hoagland's solution (Sharma et al., 2018).

The $\mathrm{pH}$ of the water has a major impact on nitrification. The reaction rate of nitrification in a growing biofilter (root growth centre) produced by a solution of hydroponic nutrients, $\mathrm{NO}_{3}{ }^{-}$and two $\mathrm{pH}$ levels (6.5 and 8.5) were developed by (Tyson et al., 2007). At $\mathrm{pH} 8.5$, the rate of ammonia oxidation increased (1.75) compared to the rate of nitrite oxidation (1.3), resulting in $\mathrm{NO}_{2}^{-}$ accumulation at values similar to those damaging to plants (high value of $4.2 \mathrm{mg} \mathrm{L}^{-1} \mathrm{NO}_{2}{ }^{-}$). Another issue associated to $\mathrm{pH} 8.5$ is the potential for increasing quantities of non-ionized ammonia, which lowers nutritional content in rainwater plants (Toshiki Asao, 2012). 
Plants adjust electrical conductivity (EC) while they absorb nutrients and water from the nutrient solution. A rise in the EC value has been reported in an open system with nutrient solution recycling due to the accumulation of high amounts of specific ions such as bicarbonate, sulfate, and chloride. (Zekki et al., 1996). So, the recycling of nutrient solutions represents a point of discussion. In addition, substrates can retain ions, and consequently, the EC increases. Controlled leaching with good quality water is an option for reducing salt nutrient solutions for hydroponic systems (Cácere, 2004). Mulching with polypropylene sheets reduces water usage, improves water efficiency, and lowers the EC of the solution; as a result, mulching is a viable method for EC reduction (Farina et al., 2003). Carmassi et al., (2005) established a general model for variations in ion concentration and $\mathrm{EC}$ recycling nutrient fluid during a closed-loop soilless culture supported by hydroponically grown plants.

The $\mathrm{pH}$ of hydroponic systems changes as the plants develop. As a result, in hydroponic solutions, $\mathrm{pH}$ regulation is necessary. $\mathrm{pH}$ changes of less than 0.1 units have little effect. Most species benefit from a $\mathrm{pH}$ range of 5.5 to 6.5 for nutrient availability from most nutrient solutions, while species vary widely and develop best outside of this range (Sardare and Adamane, 2013). Table 2 shows the appropriate range of $\mathrm{EC}$ and $\mathrm{pH}$ values for several hydroponic crops.

Table 2: $\mathrm{EC}\left(\mathrm{dSm}^{-1}\right)$ and $\mathrm{pH}$ ranges for hydroponic plants (Sardare and Admane, 2013)

\begin{tabular}{|l|l|l|}
\hline Crops & EC $\left(\mathbf{d S m}^{-1}\right)$ & $\mathbf{p H}$ \\
\hline Asparagus & 1.4 to 1.8 & 6.0 to 6.8 \\
\hline Tomato & 2.0 to 4.0 & 6.0 to 6.5 \\
\hline African violet & 1.2 to 1.5 & 6.0 to 7.0 \\
\hline Basil & 1.0 to 1.6 & 5.5 to 6.0 \\
\hline Banana & 1.8 to 2.2 & 5.5 to 6.5 \\
\hline Broccoli & 2.8 to 3.5 & 6.0 to 6.8 \\
\hline Cabbage & 2.5 to 3.0 & 6.5 to 7.0 \\
\hline Cucumber & 1.7 to 2.0 & 5.0 to 5.5 \\
\hline Egg plant & 2.5 to 3.5 & 6.0 \\
\hline Lettuce & 1.2 to 1.8 & 6.0 to 7.0 \\
\hline Peppers & 0.8 to 1.8 & 5.5 to 6.0 \\
\hline Spinach & 1.8 to 2.2 & 6.0 to 7.0 \\
\hline
\end{tabular}

\section{Water use efficiency in hydroponics systems}

The drained water collected after irrigation was used to calculate overall water usage. The total amount of water utilised by plants (litres per tray) was estimated (Ningoji et al., 2020).

Total water use $=$ total water delivered to irrigation + total water drained from trays (Hatfield et al., 2001).

According to the below equation (Eq.1.1), water usage efficiency in $\mathrm{kg} / \mathrm{m}^{3}$ was calculated (Manju H.M., et al., 2020).

$$
W e=\frac{\mathrm{Tp}}{\mathrm{Tw}}
$$

Where,

$$
\begin{aligned}
& \mathrm{We}=\text { Water use efficiency }\left(\mathrm{kg} / \mathrm{m}^{3}\right) \\
& \mathrm{Tp}=\text { Total production }(\mathrm{kg}) \\
& \mathrm{Tw}=\text { Total water use }(\text { liter })
\end{aligned}
$$

\section{Future scope of hydroponics}

Hydroponics systems are a rapidly growing sector of agriculture, and they can produce food products in the future. People will prefer hydroponics and aeroponics to agricultural cultivation as the population grows and arable land reduces caused by inadequate land management. Because of the city's rising population, land in Tokyo is exceedingly valuable. The government has turned to hydroponic rice farming to feed its growing population while preserving valuable land. Because the environment is totally regulated with hydroponics, four crop cycles can be done annually instead of the typical single crop. In Israel, where the weather is arid, hydroponics has proven to be effective. The procedure is totally automated, with robots operating on assembly line-style systems similar to those found in factories. In Africa and Asia, where both water and food are limited, hydroponics has the potential to feed millions of people. Hydroponics will also play a major role in the space program's future. NASA has large hydroponics exploration efforts that will enable future, longterm habitation of Mars or the Moon, in addition to current space technologies (Sardare et al., 2013). The hydroponic business in India is predicted to grow dramatically in the near future. It is essential to design low-cost hydroponic structures that reduce reliance on human workers and lower overall set-up and operation expenses in order to 
encourage commercial hydroponic farms (Sharma et al., 2018, Manju et al., 2020). In the future, the goal of organic nutrient work should be to be able to standardize the methods, additions, and results of organic nutrient solutions for small-scale organic farmers. To ensure consumer confidence in organic, foods must be as safe and healthy as conventional alternatives. Hydroponic farming can yield highquality, efficiently produced veggies for urban and rural farms, as well as for future research beyond Tera Fera, with the right nutrient solutions, temperatures, and other environmental variables (Ferguson et al., 2014).

\section{Conclusion}

The hydroponics industry is going to be the fastestgrowing industry in the future. In India, the urban concrete empire is growing day by day, adopting soil-less culture to help increase production and quality of the products in order to ensure our country's food security. In hydroponics systems by use of proper nutrient solutions, with controlled temperatures, and environmental conditions, produced high-quality crops. Nowadays seed

\section{References}

Anbukkani, P. 2016. Economic analysis of dairy farming in dry Arias-Fernandez, R., López-Mosquera, M. E., \& Seoane, S. (2000, March). Coal-Mine Spoil Reclaiming as Substrate for" Cultivation Without Soil" in Petunia. In $V$ International Symposium on Protected Cultivation in Mild Winter Climates: Current Trends for Sustainable Technologies 559, 619-625.

Asao, T. (Ed.). (2012). Hydroponics: A standard methodology for plant biological researches. BoD-Books on Demand.

Buchanan, D. N., \& Omaye, S. T. (2013). Comparative study of ascorbic acid and tocopherol concentrations in hydroponic-and soil-grown lettuces.

Burrage, S. W. (1992, March). Nutrient film technique in protected cultivation. In Symposium on Soil and Soilless Media under Protected Cultivation in Mild Winter Climates 323, 23-38.

Carmassi, G., Incrocci, L., Maggini, R., Malorgio, F., Tognoni, F., \& Pardossi, A. (2005). Modeling salinity build-up in recirculating nutrient solution culture. Journal of plant nutrition, 28(3), 431-445.

Despommier, D. (2009). The rise of vertical farms. Scientific American, 301(5), 80-87. germination and hydroponic grass production are used for good nutrition. Various seeds grown by hydroponics system can be appropriately used on small farms, for producing high-quality products. Researchers obtained high-quality goods using the hydroponic system, which are likely to fulfil market expectations. Our worry with the soilless cultivation technique reflects a lack of understanding of its advantages, which include a flexible growth approach that gives the grower complete control over the growing conditions, including the active root zone. To assist ecoagriculture, these methods, which can increase the efficiency of water usage while maintaining its quality, should be adopted on a larger scale. We need further research to develop more productive and cost-effective organic nutrient solutions and improve hydroponic crop production systems. To Increase the commercialization of hydroponic systems, it is essential to design low-cost hydroponic structures that reduce reliance on human workers and lower overall set-up and operation expenses in order to encourage commercial hydroponic farms.

Domingues, D. S., Takahashi, H. W., Camara, C. A., \& Nixdorf, S. L. (2012). Automated system developed to control $\mathrm{pH}$ and concentration of nutrient solution evaluated in hydroponic lettuce production. Computers and electronics in agriculture, 84, 53-61.

Dunn, B., \& Shrestha, A. (2013). Hydroponics "Oklahoma State University Cooperative ExtensionService", <http://osufacts.okstate.edu/documshar e/dsweb/Get/Document-6839/HLA6442web.Pdf $>$ (octoberl, 2013).

Farina, E., Allera, C., Paterniani, T., \& Palagi, M. (2003, July). Mulching as a technique to reduce salt accumulation in soilless culture. In International Symposium on Managing Greenhouse Crops in Saline Environment 609, 459-466.

Ferguson, S. D., Saliga III, R. P., \& Omaye, S. T. (2014). Investigating the effects of hydroponic media on quality of greenhouse grown leafy greens. International Journal of Agricultural Extension, 2(3), 227-234.

Grewal, H. S., Maheshwari, B., \& Parks, S. E. (2011). Water and nutrient use efficiency of a low-cost hydroponic greenhouse for a cucumber crop: An Australian case study. Agricultural Water Management, 98(5), 841-846.

Grigas, A., Kemzūraitè, A., \& Steponavičius, D. (2019). Hydroponic devices for green fodder production: a review. In Rural development 2019: research and innovation for 
bioeconomy (RD2019)[elektroninis išteklius]: 9th international scientific conference, September 26-28, 2019, Agriculture Academy of Vytautas Magnus University. Akademija: Agriculture Academy of Vytautas Magnus University.

Hatfield, J. L., Sauer, T. J., \& Prueger, J. H. (2001). Managing soils to achieve greater water use efficiency: a review.

Hochmuth, G. J., \& Hochmuth, R. C. (2001). Nutrient solution formulation for hydroponic (perlite, rockwool, NFT) tomatoes in Florida. HS796. Univ. Fla. Coop. Ext. Serv., Gainesville.

Hussain, A., Iqbal, K., Aziem, S., Mahato, P., \& Negi, A. K. (2014). A review on the science of growing crops without soil (soilless culture)-a novel alternative for growing crops. International Journal of Agriculture and Crop Sciences, 7(11), 833.

Jensen, M. H., \& Malter, A. J. (1995). Protected agriculture: a global review.

Guo, J., Yan, Y., Dong, L., Jiao, Y., Xiong, H., Shi, L., ... \& Shi, A. (2019). Quality Control Techniques and Related Factors for Hydroponic Leafy Vegetables. HortScience, 54(8), 1330-1337.

Jones, J. (2012). Ideal hydroponic growing system. Practical Hydroponics and Greenhouses, (124), 42-44.

Joseph, A. (2014). Technical feasibility and economic viability of hydroponic systems for vegetable cultivation (Doctoral dissertation, TNAU, Coimbatore).

Jovicich, E. J., Cantliffe, D. J., \& Vansickle, J. J. (2004, March). US imports of colored bell peppers and the opportunity for greenhouse production of peppers in Florida. In VII International Symposium on Protected Cultivation in Mild Winter Climates: Production, Pest Management and Global Competition 659, 81-85.

Khan, F. A. A. (2018). A review on hydroponic greenhouse cultivation for sustainable agriculture. International Journal of Agriculture Environment and Food Sciences, 2(2), 59-66.

Manju, H. M., Singh, M., Yadav, K. K., \& Bhakar, S. R. (2020). Development of Solar Operated Hydroponic Fodder Production System. Int. J. Curr. Microbiol. App. Sci, 9(11), 2936-2942.

Manzocco, L., Foschia, M., Tomasi, N., Maifreni, M., Dalla Costa, L., Marino, M., ... \& Cesco, S. (2011). Influence of hydroponic and soil cultivation on quality and shelf life of ready-to-eat lamb's lettuce (Valerianella locusta L. Laterr). Journal of the Science of Food and Agriculture, 91(8), 1373-1380.
Nielsen, C. J., Ferrin, D. M., \& Stanghellini, M. E. (2006). Efficacy of biosurfactants in the management of Phytophthora capsici on pepper in recirculating hydroponic systems. Canadian Journal of Plant Pathology, 28(3), 450460.

Ningoji, S. N., Thimmegowda, M. N., Boraiah, B., Anand, M. R., Murthy, R. K., \& Asha, N. N. (2020). Effect of Seed Rate and Nutrition on Water Use Efficiency and Yield of Hydroponics Maize Fodder. Int. J. Curr. Microbiol. App. Sci, 9(1), 71-79.

Okemwa, E. (2015). Challenges and opportunities to sustainability in aquaponic and hydroponics systems. Int $J$ Sc Res Inn Tech, 2(11), 23.

Palm, H. W., Knaus, U., Appelbaum, S., Goddek, S., Strauch, S. M., Vermeulen, T., ... \& Kotzen, B. (2018). Towards commercial aquaponics: a review of systems, designs, scales and nomenclature. Aquaculture international, 26(3), 813-842.

Polycarpou, P., Neokleous, D., Chimonidou, D., \& Papadopoulos, I. (2005). A closed system for soil less culture adapted to the Cyprus conditions. F. El Gamal, AN Lamaddalen, C. Bogliotti, and R. Guelloubi. Nonconventional water use, 237-241.

Rouphael, Y., \& Colla, G. (2005). Growth, yield, fruit quality and nutrient uptake of hydroponically cultivated zucchini squash as affected by irrigation systems and growing seasons. Scientia Horticulturae, 105(2), 177-195.

Sardare, M. D., \& Admane, S. V. (2013). A review on plant without soil-hydroponics. International Journal of Research in Engineering and Technology, 2(3), 299-304.

Schnitzler, W. H. (2012, May). Urban hydroponics for green and clean cities and for food security. In International Symposium on Soilless Cultivation 1004, 13-26.

Sharma, N., Acharya, S., Kumar, K., Singh, N., \& Chaurasia, O. P. (2018). Hydroponics as an advanced technique for vegetable production: An overview. Journal of Soil and Water Conservation, 17(4), 364-371.

Suma, T. C., Kamat, V. R., Sangeetha, T. R., \& Reddy, M. (2020). Review on hydroponics green fodder production: Enhancement of nutrient and water use efficiency. IJCS, 8(2), 2096-2102.

Taig, L. (2012). Greenhouse technical management for the future. Practical Hydroponics and Greenhouses, (122), 3032.

Takakura, T. (2014). Greenhouse production in engineering. Mathematical and Control Applications in Agriculture and Horticulture, 5, 19. 
Tyson, R. V., Simonne, E. H., Davis, M., Lamb, E. M., White, J. M., \& Treadwell, D. D. (2007). Effect of nutrient solution, nitrate-nitrogen concentration, and $\mathrm{pH}$ on nitrification rate in perlite medium. Journal of Plant Nutrition, 30(6), 901-913.

Tyson, R. V., Simonne, E. H., White, J. M., \& Lamb, E. M. (2004, December). Reconciling water quality parameters impacting nitrification in aquaponics: the $\mathrm{pH}$ levels.
In Proceedings of the Florida State Horticultural Society (Vol. 117, pp. 79-83).

Zekki, H., Gauthier, L., \& Gosselin, A. (1996). Growth, productivity, and mineral composition of hydroponically cultivated greenhouse tomatoes, with or without nutrient solution recycling. Journal of the American Society for Horticultural Science, 121(6), 1082-1088. 